$\xi=-1$

\title{
Feed Solution in the Pipeline aith the Compensators Mortar Pump of Various Design Solutions Pressure Pulsations Degree Determination
}

\author{
Bogdan Korobko $^{1 *}$, Viktor Virchenko ${ }^{2}$, Mykola Shapoval ${ }^{3}$

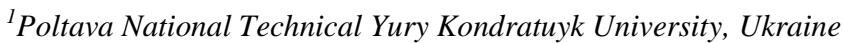 \\ ${ }^{2}$ Poltava National Technical Yury Kondratuyk University, Ukraine \\ ${ }^{3}$ Poltava National Technical Yury Kondratuyk University, Ukraine \\ *Corresponding Author E-Mail:Bogdan.Korobko@Ukr.Net
}

\begin{abstract}
The article deals with the mortar pump with ball spring-loaded suction and delivery valves, a special insert in the suction chamber and compensators of various design solutions. Comparative analysis to determine the degree of pressure pulsation of the mortar pump with various compensators is presented. On the basis of theoretical and experimental studies, it has been proven that mortar pump with a combined compensator of increased volume has lower pulsation levels relative to the pulsations in the mortar pump compensator with combined pressure pulsations compensator. Rational parameters of the compensator of increased mortar's volume are defined.
\end{abstract}

Keywords: mortar pump with a combined compensator of increased volume, the degree of pressure pulsations, solution mobility, reduced volume of compensator.

\section{Introduction}

\subsection{Overview}

Qualitative performance of plastering works requires pumps the uninterrupted and low-pulse feeding of semidry solutions. Large feeding pulsation enlarges the solution rebound from the work surface and disables the solution application onto the work surface due to the shocks of the hose and nozzle, which results in lowering the quality of the plaster work and increasing the expenditure of solution, time and money.

Compensators in the form of air chamber of different volumes are used in a modern single-piston mortar pumps for reducing pressure pulsations.

But air compensators, along with advantages, have significant disadvantages: compressed air is in a direct contact with the pumped solution and is intensively removed from the compensator during the operation of the mortar pump. Also, the air compensators have insufficient volume for effective smoothing of the pressure pulsations.

The development of new designs of compensators and improvement of the existing ones is an urgent problem for ensuring the efficient operation of mortar pumps.

\subsection{Relevance}

Analysis of recent research sources indicates that not all the solution pumps satisfy the short pulse feed of solution. Therefore, it is necessary to create a mortar pump of simple design, which will provide a low degree of pulse pressure of the solution feed. Selection of the unsettled general problem parts. It is necessary to conduct comparative theoretical studies to determine the indexes of compensators on the basis of a single-piston mortar pump and to confirm their practicability experimentally.

\subsection{The Aim}

To ensure smoothening of pressure pulsations to a moderate level, combined air compensator consisting of two chambers must be used as part of the mortar pump. One chamber must be with free air and separated by a float, and the other - with a compressed one.

\section{Main Body}

Mortar pump with a combined pressure pulsation compensator (Fig. 1) [3] does not fully satisfy the effective work, namely the reduced levels for the pressure pulsation degree of the solution feed. The increase in the level of the pressure pulsation in this mortar pump is due to the air removal from the solution from the cylindrical chamber of the compensator, which lessens the reduced compensated volume. Therefore, on the basis of this mortar pump, a new design of the mortar pump with a combined compensator of the increased volume (Fig. 2) was created.

Mortar pump with a combined compensator of increased volume, which is proposed for consideration, works as follows (Fig. 2). After switching off the electric motor 1 , piston 8 performs reciprocating motion from the V-belt transmission 2 and the gear transmission, which consists of a wheel 3 and shaft gear 5. During the piston distance to the left, a dilution is generated in the suction chamber 6 , and the solution enters the chamber 6 through the open suction valve 14 . Since the pressure valve 15 is closed, with the steady-state work process of the mortar pump, delivery pressure in the pressure inlet 17 is reduced, compressed air in the cylindrical chamber 20 (as well as in a closed chamber 21 at elevated feed 
pressure higher than $0.7 \mathrm{MPa}$ ) expands, resulting in the volume of air in the chambers 20,21 squeezes the solution into the pressure inlet 17.

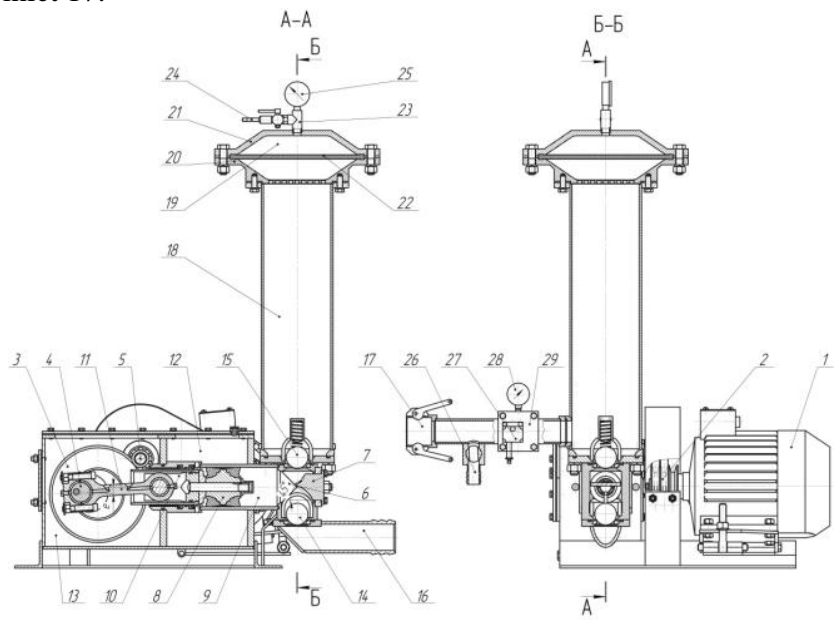

Fig. 1: Constructive scheme of a single-piston mortar pump with pulsation pressure compensator

1 - electric motor; 2 - V-belt transmission; 3 - gear wheel; 4 - crank shaft; 5 - shaft gear; 6 - suction chamber; 7 - special insert; 8 - piston; 9 working cylinder; 10 - slider; 11 - connecting rod; 12 - camera; 13 gearbox housing; 14, 15 - suction and pressure spring-loaded ball valves;

16 - suction pipe; 17 - pressure inlet; 18 - cylindrical chamber; 19 -

closed camera; 20 - base; 21 - upper cap; 22 - a rubber-coated diaphragm;

23 - reduction pipe; 24 - nipple; 25,28 - manometer; 26 - pressure reduction valve; 27 - pressure relay; 29 - diaphragm camera

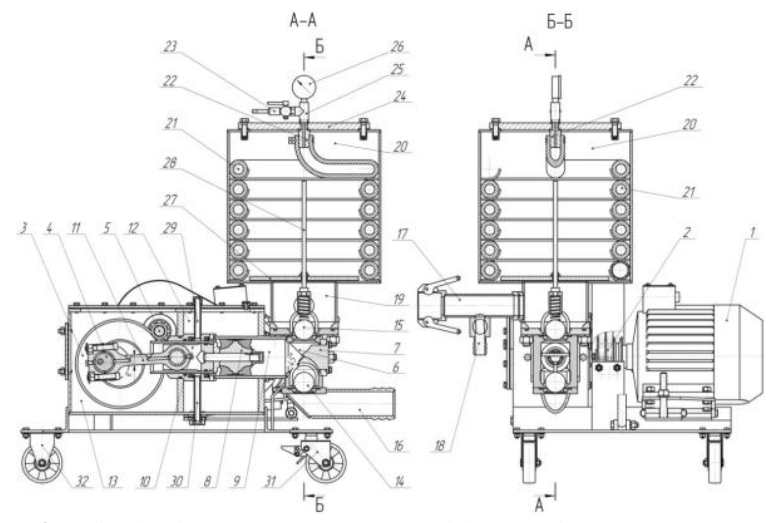

Fig. 2: Single-piston mortar pump with combined compensator of increased volume

1 - electric motor; 2 - V-belt transmission; 3 - gear wheel; 4 - crank shaft; 5 - gear shaft; 6 - suction chamber; 7 - special cylindrical insert; 8 piston; 9 - working cylinder; 10 - slider; 11 - connecting rod; 12 - camera; 13 - gearbox housing; 14, 15 - suction and pressure spring-loaded ball valves; 16,17 - suction and pressure inlets; 18 - pressure reduction valve; 19 - pressure chamber; 20 - cylindrical chamber; 21 - closed camera; 22 the connection branch of the unit of air swapping; 23 - nipple; 24 - cap 25 - reduction pipe, 26 - pressure gauge; 27 - float restrictor; 28 - guide rod; 29,30 - canal pipes; 31,32 - a pair of wheels.

During the piston distance to the right, the suction valve 14 closes, and the pumped medium passes through the open suction valve 14 to the cylindrical chamber 19 . One part of this medium is expulse into the pressure inlet 16 , and the second one fills the chamber 20 , compressing the air through the float restrictor 27, which minimizes the removal of the air volume from the pumped solution by limiting air contact with the solution, moving up or down depending on the increase in the feed pressure.

A special cylindrical insert 7 is installed in the suction chamber 6 , which reduces significantly the backflows through the suction valve 14 in the pressure cycle due to the more fixed direction of the solution flow on the ball, which prevents it from hanging, especially when pumping the solutions of reduced mobility. Also, the presence of a special cylindrical insert 7 essentially reduces the "harmful volume" of the suction chamber 6.
According to the assumption, mortar pump with the combined pressure compensator (Fig. 1) and combined compensator of the increased volume (Fig. 2) should provide the solution feed into the pressure pipe in suction and pressure cycle in equal volumes.

This is due to the fact that the working pressure of the solution at the outlet to the pressure pipe varies during the operation cycle of the mortar pump in the same ranges - in the pressure cycle from the minimum value to the maximum one, and in the suction cycle, on the contrary, from the maximum to the minimum.

This assumption makes it possible to assume that one part of the actual working volume of the piston is consumed in the pressure cycle to feed the solution into the pipeline, and the second part enters the bell jar of the combined compensator, reducing the volume of compressed air in it and increasing level of its pressure. One-piston screed, which is equipped with a mechanical drive with a crank mechanism and one of the two combined compensators (Fig. 1, 2), shall supply the working environment in half-cycle injection, and in half-cycle absorption occurs closing the discharge valve and squeezing the second part of the solution in the discharge pipe a cylindrical chamber by expanding the compensating air volume compensator.

Analytical studies performed mortar pressure changes during the cycle, taking into account the law of the piston and the combined action of the compensator in which the crank shaft axis shifted down the axis of the piston in size $e$ (Fig. 3) The.

Offset crank axle shaft axis piston down to the size $e$ of the piston provides law in which increasing pressure to maximize the value held earlier than the piston reaches the right "dead" point, which in turn positively affects the level of pressure fluctuations during the cycle of the pump.

The movement of the piston in the coordinate system $x y$ depending on the angle of rotation of the crank shaft $\varphi$ can be represented as (Fig. 3)

$\left\{\begin{array}{l}x_{A}=R \cdot(1-\cos \varphi), \\ y_{A}=R \cdot \sin \varphi .\end{array}\right.$

Due to the fact that rod $l$ when you turn the crank will change its angle of inclination to the horizontal, $\alpha$ its horizontal projection is less than the length of the connecting rod $l$ to size

$l-\sqrt{l^{2}-(R \cdot \sin \varphi-e)^{2}}$.

Because coordinate $x$ the piston (point $\mathrm{B}$ in Fig. 3), which is measured from the extreme left position of the $\mathrm{B}(\varphi=0)$, will compose

$x_{B}=R \cdot(1-\cos \varphi)-\left[l-\sqrt{l^{2}-(R \cdot \sin \varphi-e)^{2}}\right]$,

where $R$ - the radius of the crank; $l$ - the length of the connecting rod; $e$ - crank deflection axis height axis piston.

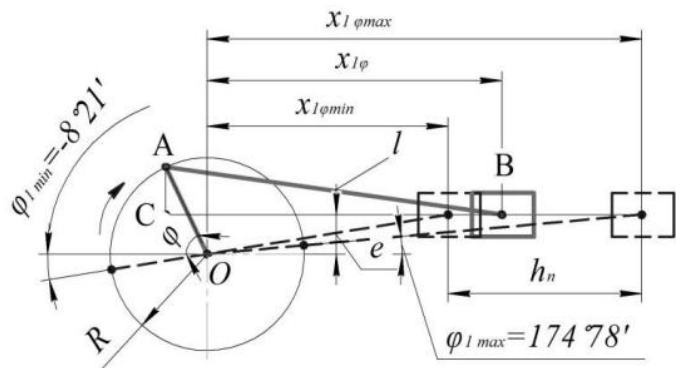

Fig. 3: The kinematics actuator piston pump with combined compensators different design solutions 
Then stroke for pumping solution for the full cycle of the pump will be (at $\varphi=0 . .2 \pi$ ) even with:

$$
\begin{aligned}
& -0 \leq \varphi \leq \pi, x_{1}=R \cdot(1-\cos \varphi)-\left[l-\sqrt{l^{2}-(R \cdot \sin \varphi-e)^{2}}\right] \\
& -\pi \leq \varphi \leq 2 \pi, \quad x_{2}=0
\end{aligned}
$$

Intact injection $(\pi \leq \varphi \leq \pi)$ one part of the fluid solution will become a mowed out a discharge pipe and the other part will fill the air chamber compensator, reducing the volume of the chamber to $\Delta V_{1}$ size.

To determine corners "dead" pixels and points where the speed of the working body is equal to zero, to determine the position of points of beginning and end of the injection cycle. Therefore, the dependence of the movement of the piston (point B) (Fig. 4) of angle of $\phi$ the crank rotation will look like

$$
x_{B}^{\prime}=R \cdot \sin \varphi-\frac{(R \cdot \sin \varphi-e) \cdot R \cdot \cos \varphi}{\sqrt{l^{2}-(R \cdot \sin \varphi-e)^{2}}} .
$$

Using the parameters in the equation $R=40 \mathrm{~mm}, l=180 \mathrm{~mm}$, $e=20 \mathrm{~mm}$ and equating $x_{B}^{\prime}$ to zero derived crank angles $\varphi_{0}=-8,21^{\circ}$ and $\varphi_{1}=174,78^{\circ}$ defining the relevant provisions outer "dead" points of the piston.

The value $\varphi_{0}$ and $\varphi_{1}$ presented constructive sizes for research and industrial design pump, which is studied in this thesis with two kinds of composite jacks.

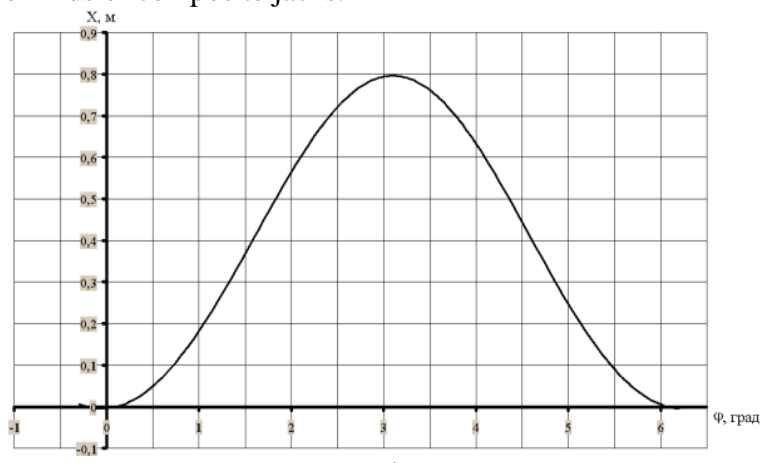

a)

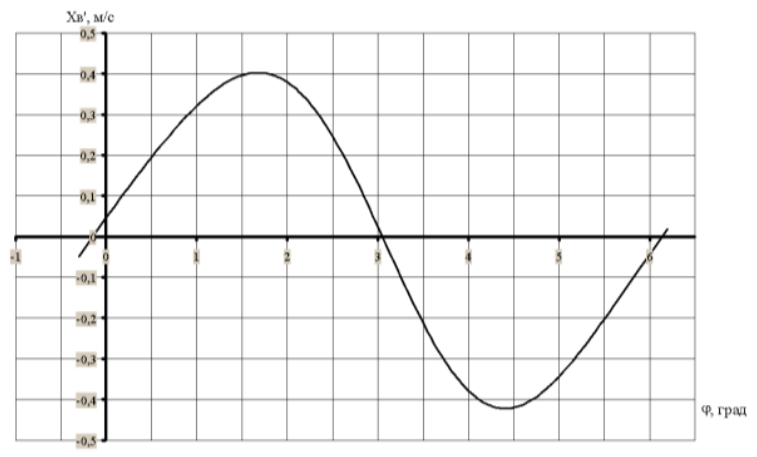

b)

Fig. 4: Dependence (a) movement of the piston pump (point C) (b) speed of rotation of the crank angle

Cycle of pump is divided into two parts: the beat pumping in the range $\varphi_{0}$ from $-8.21^{0}$ to $174.78^{0}$ and absorption cycle -at $\varphi_{1}$ from $17478^{0}$ to $351.79^{0}$.

In stroke injection carried out two processes: increasing the volume of solution in the compensator due to its filing of the piston and the reduction in volume due to the filing of the solution in the discharge pipe.

Whereas it is accepted that changes in pressure pumping solution in bars and absorption occur in the same limits as the stream of solution at the outlet of the discharge pipeline during pump compensators combined with moderate because supply solution during the cycle does not change. Under this condition change in volume of compressed air compensator when changing angle $\varphi$ to compose

$$
\begin{aligned}
& 0 \leq \varphi \leq \pi, \quad \Delta V_{1}=F_{n} \cdot\left(x_{1}-\frac{h_{n}}{2 \pi} \cdot \varphi\right) \\
& \pi \leq \varphi \leq 2 \pi, \quad \Delta V_{2}=F_{n} \cdot\left[\left(x_{n}-\frac{h_{n}}{2}\right)-\frac{h_{n}}{2 \pi} \cdot(\varphi-\pi)\right],
\end{aligned}
$$

where $\Delta V_{1}$ - to change the volume of compressed air compensator in tact injection piston relative to the volume of compressed air $\varphi=0$ at; $\Delta V_{2}$ - the same as in the suction stroke of the piston, i.e. $\varphi=0 . . .2 \pi$ when; $x_{1}$ - the law of the piston depending on the angle $\varphi$ of injection cycle $(\varphi=0 \ldots \pi)$ is defined by the equation; $h_{n}$ - the total value of the $h_{n}=x_{1}^{\max }-x_{1}^{\min }$ stroke, also determined by the equation, this value is slightly different from $2 R$ the axis by the offset crank shaft axis piston; $x_{n}$ - the value $x_{1}$ at $\varphi=\pi$.

According to Boyle's law,

$V_{\varphi}=p_{\text {amu }} \cdot \frac{V_{\text {комn }}}{p_{\varphi}}$ where $p_{\varphi}=p_{\text {amu }} \cdot \frac{V_{\text {комn }}}{V_{\varphi}}$,

where $V_{\varphi}$ - the current volume of compressed air at an angle $\varphi$ compensator; $V_{\text {коми }}$ - reduced to normal conditions $p_{\text {amu }}=0,1(\mathrm{MPa})$ air volume compensator; $p_{\varphi}$ Compressed air pressure (and solution) at the $\varphi$ corner MPa.

Dependence 1 in Fig. 6 describes the supply solution in a cylindrical chamber joints of piston stroke injection based his laws of motion. This feed is determined by the $F_{n} \cdot x_{1}$ expression. Dependence 2 (Fig. 5) characterizes the change in volume of the solution in a cylindrical chamber equalizer when applying it to the discharge pipe during absorption, determined dependence

$q=\frac{V_{p . \partial .}}{2 \pi} \cdot \delta(\varphi)$

where $V_{p . \text { д. }}$ - true working volume of the piston.

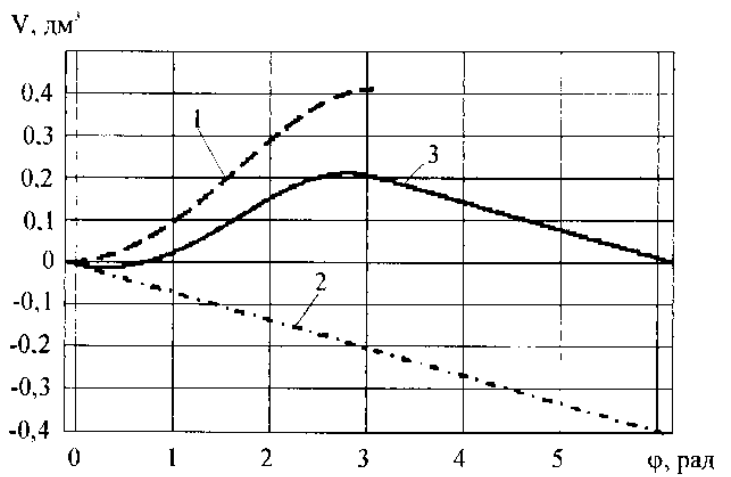

Fig. 5 Dependence of solution volume in cylindrical cells Mortar joints: 1 - from the movement of the piston, 2 - from feeding into the pipeline 3 volume of solution in a cylindrical chamber for a full cycle

Dependence 3 (Fig. 6) shows the change in volume solution in a cylindrical chamber joints during the cycle of pump.

Since $V_{\varphi}=V_{0}-\Delta V$ it is based formulas have solution for pressure change cycle of the pump 


$$
\begin{aligned}
& 0 \leq \varphi \leq \pi, \quad p_{\varphi_{\max }}=\frac{p_{\varphi_{0} \text { ати }} \cdot V_{\text {коии }}}{V_{0}-F_{n} \cdot\left(x_{1}-\frac{h_{n}}{2 \pi} \cdot \varphi\right)}, \\
& \pi \leq \varphi \leq 2 \pi, \quad p_{\varphi_{\min }}=\frac{p_{\varphi_{0} \text { ати }} \cdot V_{\text {коии }}}{V_{0}-F_{n} \cdot\left[\left(x_{\pi}-\frac{h_{n}}{2}\right)-\frac{h_{n}}{2 \pi} \cdot(\varphi-\pi)\right]} .
\end{aligned}
$$

where $V_{\text {комп }}$ - given volume of air to atmospheric pressure $p_{\text {amм }}$ compensator; $V_{0}$ - the volume of compressed air at the $\varphi=0 \quad V_{0}=p_{\text {атм }} \cdot \frac{V_{\text {коми }}}{p_{0}}$ compensator, $p_{\varphi_{0} \text { атм }}$ - the pressure of compressed air at the beginning of the cycle pump, MPa; $x_{1}-\mathrm{a}$ stroke pumping cycle, which is defined by the equation.

In these conditions, the pressure $p_{\varphi_{\max }}, p_{\varphi_{\min }}$ is determined according dependencies,

$$
\begin{aligned}
& 0 \leq \varphi \leq \pi, \quad p_{\varphi_{\max }}=\frac{p_{\varphi_{0} \text { ams }} \cdot V_{\text {коми }}}{V_{0}-F_{n} \cdot\left\{R \cdot(1-\cos \varphi)-\left[l-\sqrt{l^{2}-(R \cdot \sin \varphi-e)^{2}}\right]-\frac{h_{n}}{2 \pi} \cdot \varphi\right\}},(9) \\
& \pi \leq \varphi \leq 2 \pi, \quad p_{\varphi_{\min }}=\frac{p_{\varphi_{0} a \text { am }} \cdot V_{\text {коми }}}{V_{0}-F_{n} \cdot\left[\left(x_{\pi}-\frac{h_{n}}{2}\right)-\frac{h_{n}}{2 \pi} \cdot(\varphi-\pi)\right]} .
\end{aligned}
$$

Thus using the formula, we can determine the change in pressure during the cycle of a solution Mortar if known $R \quad l \quad e$ parameters, $F_{n}$ and $V_{\text {комп }}$ initial $p_{\min }$ pressure.

Table 2 shows estimates pulsation solution depending on the pressure.

Table 2 - Estimated value fluctuations solution depending on the pressure.

\begin{tabular}{|c|c|c|c|c|}
\hline$p_{\text {min }}, \mathrm{MPa}$ & $p_{\max }, \mathrm{MPa}$ & $\Delta p, \mathrm{MPa}$ & $p_{c p}, \mathrm{MPa}$ & $\delta, \%$ \\
\hline \multicolumn{5}{|c|}{ Screed compensator combined with pressure pulsation } \\
\hline 1.0 & 1.145 & 0.145 & 1.073 & 13.5 \\
\hline 2.0 & 2.600 & 0.600 & 2.300 & 26.0 \\
\hline 3.0 & 4.500 & 1.500 & 3.750 & 40.0 \\
\hline 4.0 & 6.700 & 2.700 & 5.350 & 503 \\
\hline \multicolumn{5}{|c|}{ Screed compensator combined with increased volume } \\
\hline 1.0 & 1,130 & 0,130 & 1,065 & 12.2 \\
\hline 2.0 & 2,300 & 0.200 & 2,150 & 14.0 \\
\hline 3.0 & 3,600 & 0,600 & 3,300 & 18.2 \\
\hline 4.0 & 5.180 & 1.180 & 4.590 & 25.7 \\
\hline
\end{tabular}

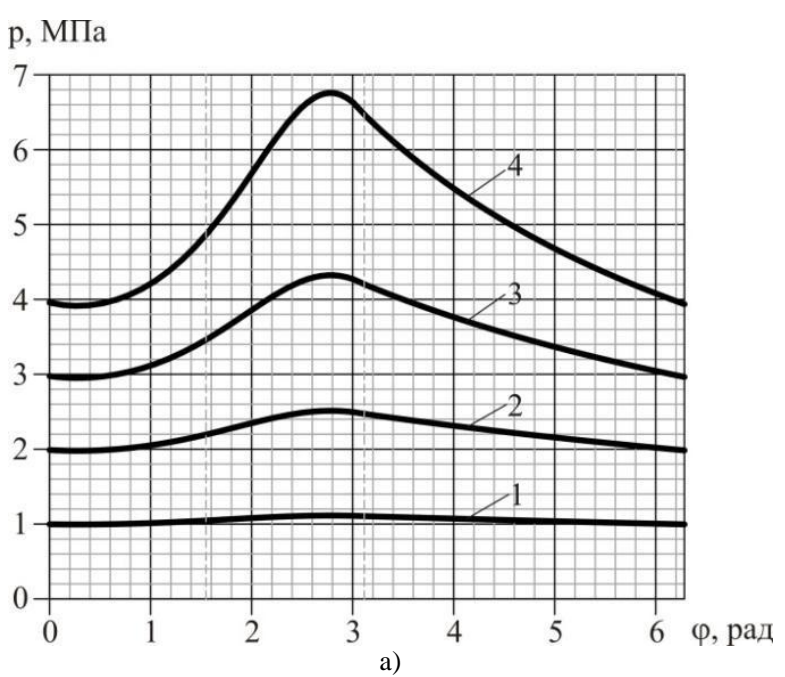

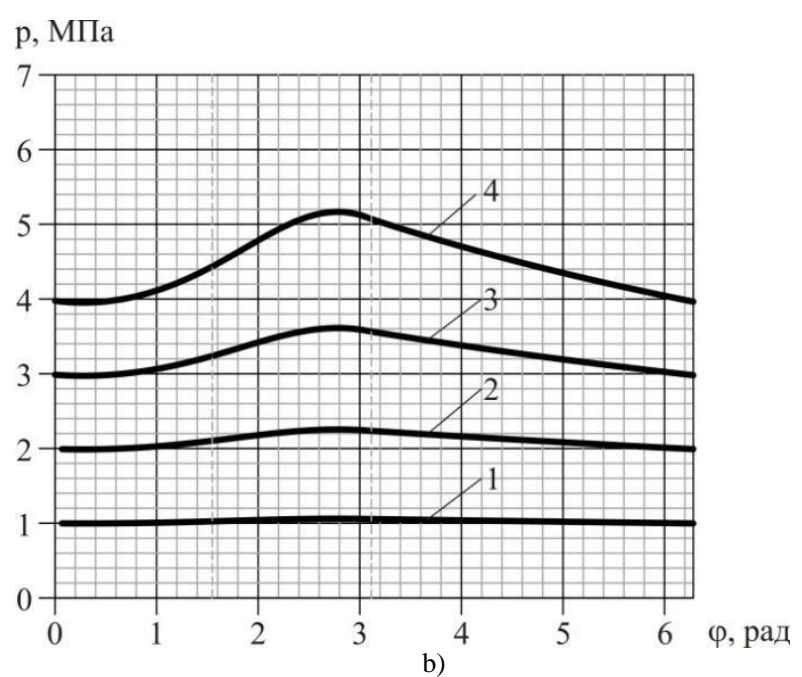

Fig. 6: Dependencies solution pressure $p=f(\varphi)$ when applying in the pipeline during the cycle of crank shaft rotation angle at $1-p_{01}=1 \mathrm{MPa}$; 2 - $p_{02}=2 \mathrm{MPa} ; 3-p_{03}=3 \mathrm{MPa} ; 4-p_{04}=4 \mathrm{MPa}$ a) to pump pulsation compensator combined with pressure; b) for pump combined with increased volume compensator

Fig. 6 are dependent changes in pressure solution is pumped over the full cycle of work to pump with combined compensators both design solutions offered, obtained by the PC using a system of equations for values of pressure $p_{01}=1 \mathrm{MPa} p_{02}=2 \mathrm{MPa}$ $p_{03}=3 \mathrm{MPa} p_{04}=4 \mathrm{MPa}$, which is determined by the degree of pulsation .

Analysis of the data indicates that during the injection cycle air pressure compensator begins to grow, reaching a maximum level $p_{\max }$ at an angle of rotation of the crank $\varphi_{0}=-8,21^{0}$ to $\varphi_{1}=174,78^{\circ}$ and then the action of air volume compensator uniformly reduced to a minimum at $\varphi_{1}=174,78^{\circ}$ to $\varphi_{2}=351,79^{0}$ sometime before the end of cycle discharge that occurs due to the displacement axis of the crank shaft axis piston down. As a result, the degree of pulsation pump decreases.

The degree of increase in pressure in the pumping cycle significantly depends on the initial pressure. Indeed, the initial pressure of $1 \mathrm{MPa}$ (Fig. 7, a) its pulsation pump when working with the combined pressure ripple compensator is $13.5 \%$, while $p_{0}=2 \mathrm{MPa}-26 \%$, almost twice as much. When the pump with increased volume compensator at $1 \mathrm{MPa}$ (Fig. 2.6, b) the pressure pulsation is $12.2 \%$, while $p_{0}=2 \mathrm{MPa}-14.0 \%$, characterizing the reduction of pulsation pump.

When pressure $p_{0}=4 \mathrm{MPa}$ (Fig. 7, b) the ripple is reduced from $50.3 \%$ to $25.7 \%$ respectively, indicating that the efficiency of the pump with increased volume compensator.

This is because the total amount of $V_{0}$ compressed air into the chambers of the equalizer early in the cycle is directly proportional to the total volume the resulted $V_{n p}$ and inversely proportional to the initial air pressure at this time.

Fig. 7 presents image depending on the total equation for the

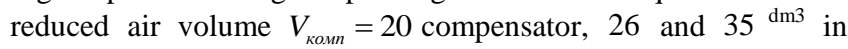
Mortar ripple compensator combined with pressure in the initial pressure $p_{0}=2 \mathrm{MPa}$, and the total for the reduced air volume $V_{\text {коми }}=41$ compensator, $47^{\text {and }} 56^{\mathrm{dm} 3}$ in Mortar with compensator larger object ' volume at an initial pressure $p_{0}=2 \quad \mathrm{MPa}$.

Graphic dependence (Fig. 7, b) indicate that the pump compensator with increased volume, a decrease in pressure fluctuations at the initial pressure $p_{0}=2 \mathrm{MPa}$ which occur in 
injection solution, compared to the pump compensator combined with pressure pulsations.

Screed compensator combined with increased volume even when the volume compensator $V_{\text {коил } 1}=41^{\mathrm{dm} 3}$ provides moderate ripple at a level $\delta=0,22$ that will spend quality plastering work during pumping.

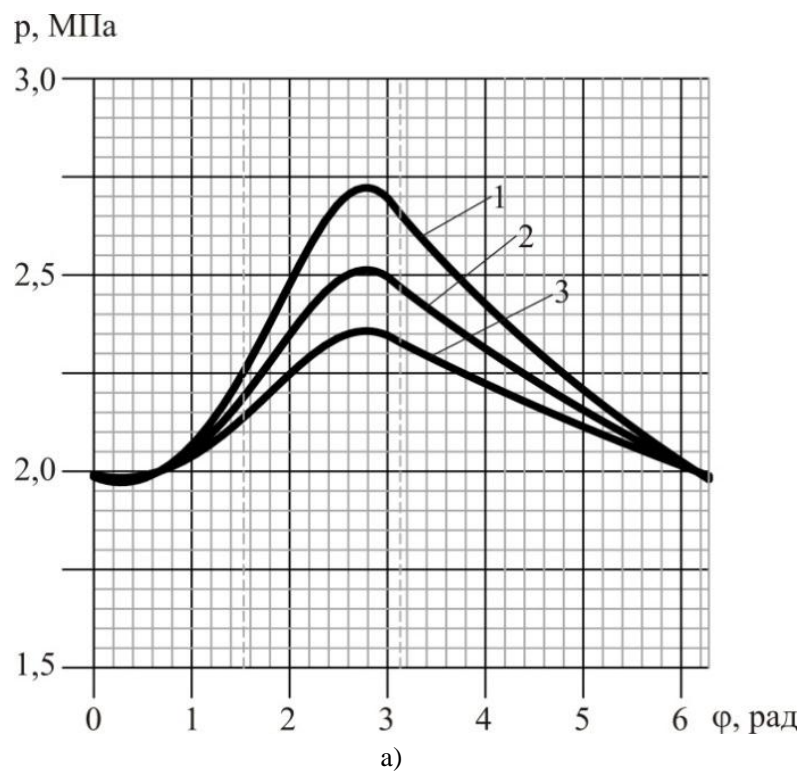

$\mathrm{p}, \mathrm{M \Pi а}$

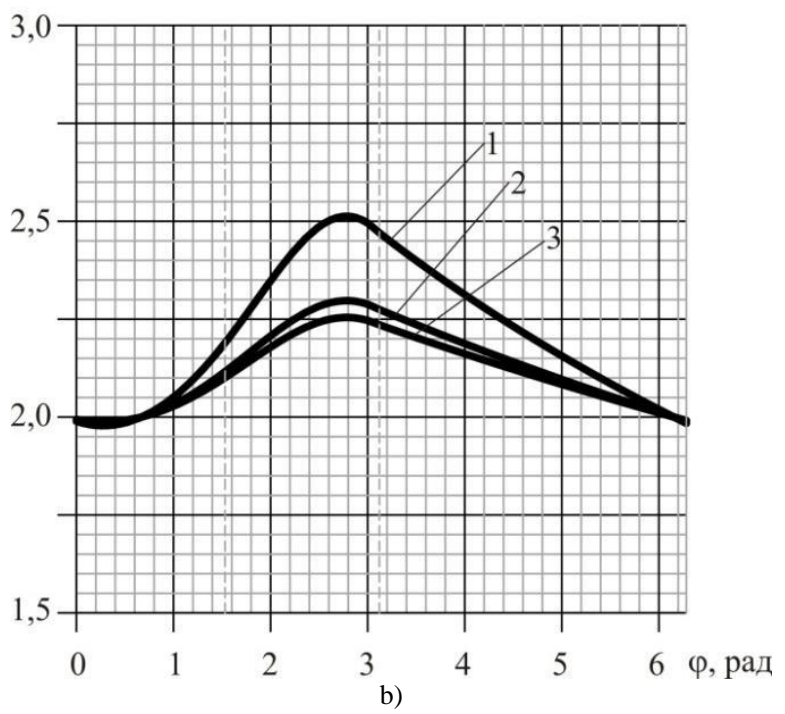

Fig. 7: Dependence pressure for reduced cycle from the total volume of air: a) pump compensator combined with pressure pulsation $1-V_{\text {коми } 1}=20 \mathrm{dm}^{3} 2-V_{\text {коип } 2}=26 \mathrm{dm}^{3} 3-V_{\text {коми } 3}=35 \mathrm{dm} 3$;

b) for pump combined with increased volume compensator 1 $V_{\text {roum } 1}=41 \mathrm{dm}^{3} 2-V_{\text {koum } 2}=47 \mathrm{dm}^{3} 3-V_{\text {roum } 3}=56^{\mathrm{dm} 3}$

Also, the maximum offset the pressure from the left corner $\varphi=\pi$ because at the end of the stroke in the stroke injection significantly reduced its speed and for a time does not provide the level of average supply per cycle. At this point, giving the solution in the discharge pipeline is not only due to the injection of stroke, but also by expanding compressed air jacks. This process is observed in the initial injection cycle time when the low rate of stroke does not ensure the desired level of supply solution. In this regard, the dependence of pressure in the initial period of discharge cycles there are areas of pressure reduction relative to the original, which is clearly seen in the dependences of high pressure $p_{0}=3$ (and4 $\mathrm{MPa})$.
This initial pressure level was chosen due to the fact that the solution feed pressure $1.5 \ldots 2.5 \mathrm{MPa}$ is most common when performing plastering work.

From the presented dependences shows that the total value of the reduced volume significantly affects the level of pressure fluctuations during the cycle of the pump. A particularly large pressure fluctuations observed when given volume of air is $20^{\mathrm{dm} 3}$ (Fig. 8 a). From these data suggest that for moderate ripple of feeding solution at $\delta=0,2 \ldots 0,25$ a given air volume compensator should be not less than $41^{\mathrm{dm} 3}$. So Screed combined with increased volume compensator work effectively against the combined compensator of pump pulsation pressure.

The solution volume must be submitted during the suction cycle due to the action of the combined compensator and equals to half of the actual working volume of the piston.

$V_{s}=\frac{\pi}{8} \cdot D_{p}^{2} \cdot h \cdot \eta_{v o l}$

where $D_{p}$ - the diameter of the piston; $h$ - piston distance; $\eta_{v o l}$ - volumetric efficiency of the mortar pump.

Solution volume to be compensated $\Delta V=\frac{V_{s}}{2}, \mathrm{dm}^{3}$.

The pressure pulsation value is determined by the formula

$\delta=\frac{p_{\max }-p_{\min }}{p_{a v}} \cdot 100, \%$,

where $p_{a v}$ - average pressure over the cycle of the solution feed,

$p_{a v}=\frac{p_{\max }+p_{\min }}{2}$.

In accordance with the constructional parameters of the combined compensators, the degree of the solution feed pressure pulsation is determined in the following conditions: the preliminary pressure of the pumped compressed air in the closed chamber $p_{c l . c}=0,5 ; 0,7 ; 1,0 \mathrm{MPa}$; the solution pressure at the beginning of the mortal pump work cycle $-p_{\min }=p_{\text {atm }} \cdot \frac{V_{\text {komp }}}{V_{1}}$, $p_{0}=p_{\text {min }}=1,0 ; 2,0 ; 3,0 \mathrm{MPa}$.

The reduced air volume in the combined compensator is determined by the dependence

$V_{c o m p}=V_{c c}+V_{c l . c} \cdot \frac{p_{c l . c}}{p_{a t m}}$

where $V_{c c}$ - free air volume in a cylindrical chamber of the compensator $\mathrm{dm}^{3} ; V_{c l . c}$ - compressed air volume in the closed chamber of compensator, $\mathrm{dm}^{3} ; p_{c l . c}$ - pressure of compressed air in the closed chamber, MPa.

The total volume of compressed air in both chambers at the beginning of the operation cycle of the mortar pump is determined by the dependence

$V_{1}=p_{\text {amu }} \cdot \frac{V_{\text {кoMn }}}{p_{\text {min }}}, \mathrm{dm}^{3}$.

Maximum pressure in cylindrical and closed chambers of the compensator per cycle

$p_{\max }=p_{a t m} \cdot \frac{V_{k o m p}}{V_{1}-\Delta V}=p_{a t m} \cdot \frac{V_{k o m p}}{p_{a t m} \cdot \frac{V_{k o m p}}{p_{\text {min }}}-\Delta V}, \mathrm{MPa}$, 
where $\Delta V$ - solution volume, which is expulsed from the cylindrical chamber of the compensator in the suction cycle due to its action. That is, $\Delta V \approx 0,203 \mathrm{dm}^{3}$.

According to the obtained dependences (14), (15), (16), (17), (18) we can determine the numerical values of the pulsation degree, which are shown in Table 2 . Their dependence on the average feed pressure in the mortar pumps is provided in Fig. 8.

Table 2: Numerical values of the pulsation degree at given parameters of compensators work

\begin{tabular}{|c|c|c|c|c|c|c|}
\hline $\begin{array}{c}p, \\
\text { МПа }\end{array}$ & $\begin{array}{c}V_{\text {comp }}, \\
\text { дм }^{3}\end{array}$ & $\begin{array}{l}p_{\text {min }}, \\
\text { МПа }\end{array}$ & $\begin{array}{l}V_{1}, \\
\text { дм }^{3}\end{array}$ & $\begin{array}{c}V_{1}-\Delta V, \\
\text { дм }^{3}\end{array}$ & $\begin{array}{l}p_{\max }, \\
\text { МПа }\end{array}$ & $\begin{array}{l}p_{a v}, \\
\text { МПа }\end{array}$ \\
\hline \multicolumn{7}{|c|}{ Mortar pump with combined pressure compensator } \\
\hline \multirow{3}{*}{0,5} & \multirow{3}{*}{20} & 1,0 & 2,00 & 1,797 & 1,11 & 1,055 \\
\hline & & 2,0 & 1,00 & 0,797 & 2,51 & 2,255 \\
\hline & & 3,0 & 0,67 & 0,467 & 4,27 & 3,635 \\
\hline \multirow{3}{*}{0,7} & \multirow{3}{*}{26} & 1,0 & 2,60 & 2,397 & 1,088 & 1,044 \\
\hline & & 2,0 & 1,30 & 1,097 & 2,370 & 2,185 \\
\hline & & 3,0 & 0,87 & 0,667 & 3,890 & 3,445 \\
\hline \multirow{3}{*}{1,0} & \multirow{3}{*}{35} & 1,0 & 3,50 & 3,297 & 1,06 & 1,030 \\
\hline & & 2,0 & 1,75 & 1,547 & 2,26 & 2,130 \\
\hline & & 3,0 & 1,17 & 0,967 & 3,62 & 3,310 \\
\hline \multirow{3}{*}{0,5} & \multirow{3}{*}{20} & 1,0 & 2,00 & 1,797 & 1,11 & 1,055 \\
\hline & & 2,0 & 1,00 & 0,797 & 2,51 & 2,255 \\
\hline & & 3,0 & 0,67 & 0,467 & 4,27 & 3,635 \\
\hline \multicolumn{7}{|c|}{ Mortar pump with combined pressure compensator of increased volume } \\
\hline \multirow{3}{*}{0,5} & \multirow{3}{*}{41} & 1,0 & 4,10 & 3,90 & 1,05 & 1,03 \\
\hline & & 2,0 & 2,05 & 1,85 & 2,22 & 2,11 \\
\hline & & 3,0 & 1,37 & 1,16 & 3,53 & 3,26 \\
\hline \multirow{3}{*}{0,7} & \multirow{3}{*}{47} & 1,0 & 4,70 & 4,50 & 1,05 & 1,02 \\
\hline & & 2,0 & 2,35 & 2,15 & 2,19 & 2,10 \\
\hline & & 3,0 & 1,57 & 1,36 & 3,448 & 3,224 \\
\hline \multirow{3}{*}{1,0} & \multirow{3}{*}{56} & 1,0 & 5,60 & 5,40 & 1,038 & 1,019 \\
\hline & & 2,0 & 2,80 & 2,60 & 2,157 & 2,078 \\
\hline & & 3,0 & 1,87 & 1,66 & 3,367 & 3,184 \\
\hline \multirow{3}{*}{0,5} & \multirow{3}{*}{41} & 1,0 & 4,10 & 3,90 & 1,05 & 1,03 \\
\hline & & 2,0 & 2,05 & 1,85 & 2,22 & 2,11 \\
\hline & & 3,0 & 1,37 & 1,16 & 3,53 & 3,26 \\
\hline
\end{tabular}

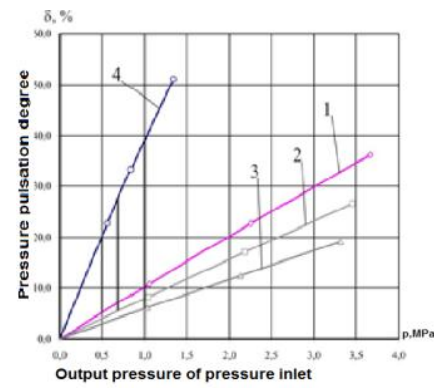

a)

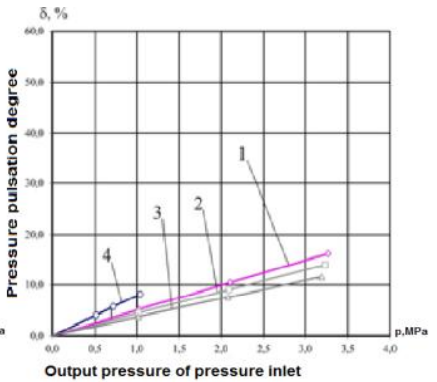

b)
Fig. 8: Dependence of the pressure pulsation degree in percentage from the constructional features of the compensators in the mortar pump: a) with a combined pressure pulsation compensator; B) with a combined compensator of the increased volume. Compensation is carried out due to air volume in cylindrical and closed chambers at pressures: 1 $p_{1}=0,5 \mathrm{MPa} ; 2-p_{2}=0,7 \mathrm{MPa} ; 3-p_{3}=1,0 \mathrm{MPa}$; only under the action of a cylindrical chamber $4-p_{4} \approx 0,1 \mathrm{MPa}$

Thus, in the compensating action of the free air only, which is contained in a cylindrical chamber and brought to a volume of 5 $\mathrm{dm}^{3}$, already at a pressure of $1 \mathrm{MPa}$, quite significant pressure pulsation (marking 4, Fig. 8, a) are observed, which reach approximately $36 \%$. However, if the supply pressure exceeds the level of the previous air pressure in the closed chamber, there is a significant decrease in the pulsation (marking 3, Fig. 8, a), but due to the increased volume of the compensator (marking 4, Fig. 8, b), the pressure pulsation in a working condition of a cylindrical chamber already at pressure $p_{1}=1,0 \mathrm{MPa}$ correspond about $8 \%$.

The pulsation reduction is explained by the connection to the compensating action of the air volume combined compensator of the closed chamber with pre-compressed air (marking 1, 2, 3, Fig. 8, b). Dependences (Fig. 8) indicate a significant decrease in the degree of pulsation in a solution pump with a combined compensator of increased volume in relation to the mortar pump with a combined compensator of the pulsations of pressure, which is explained by a larger compensating volume.

According to the results of theoretical studies to ensure a moderate level of the solution pulsation supply, reduced air volume in the compensator must be not less than $47 \mathrm{dm}^{3}$. In addition, the pressure pulsation degree will increase during pumping in a mortar pump with a combined compensator of the pressure pulsation. It is due to the air volume reduction in the cylindrical chamber, which is not observed in a mortar pump with a combined compensator of increased volume.

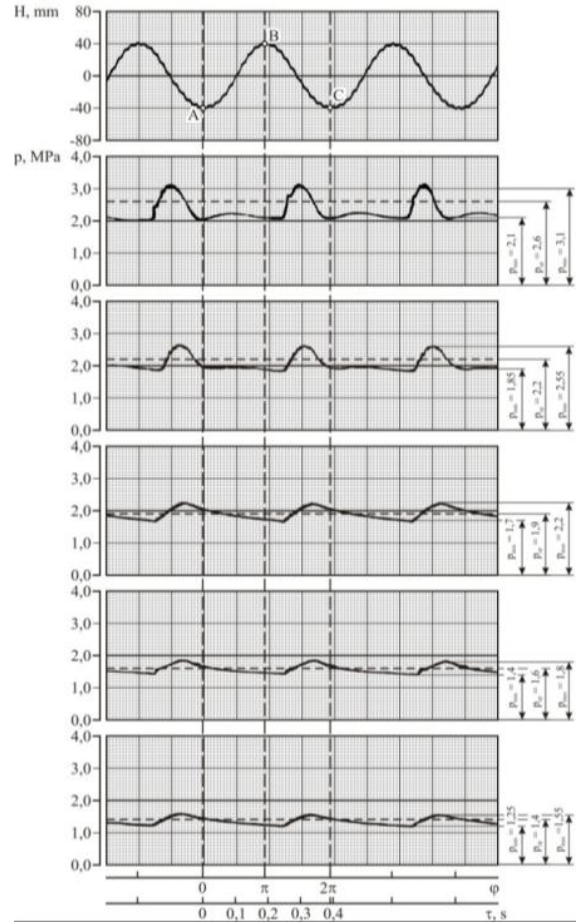

a)

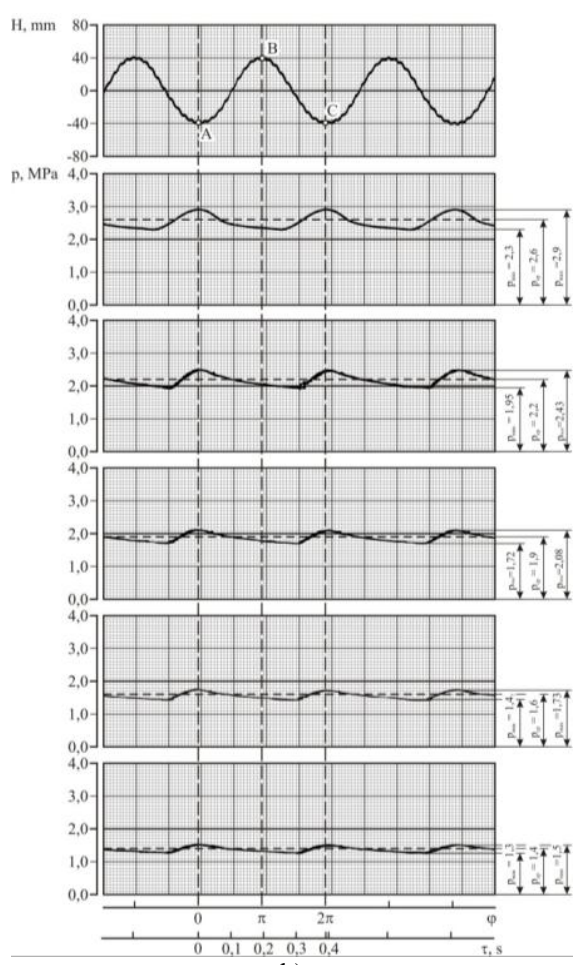

Fig. 9: Diagrams of the feed pressure of the mortar pump solution when pumping the solution $\mathrm{P}=8 \mathrm{~cm}$ : a) - with a combined pressure pulsation compensator; b) - with a combined compensator of increased volume 


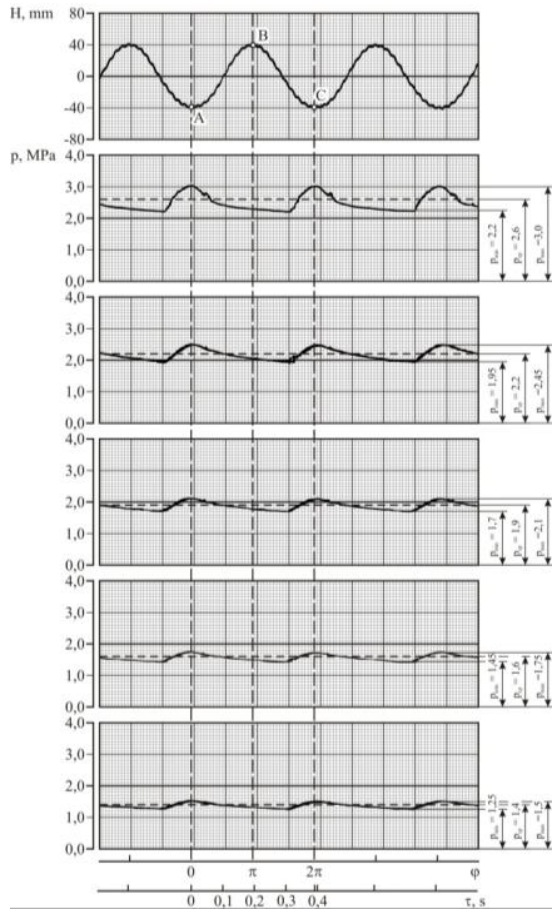

a)

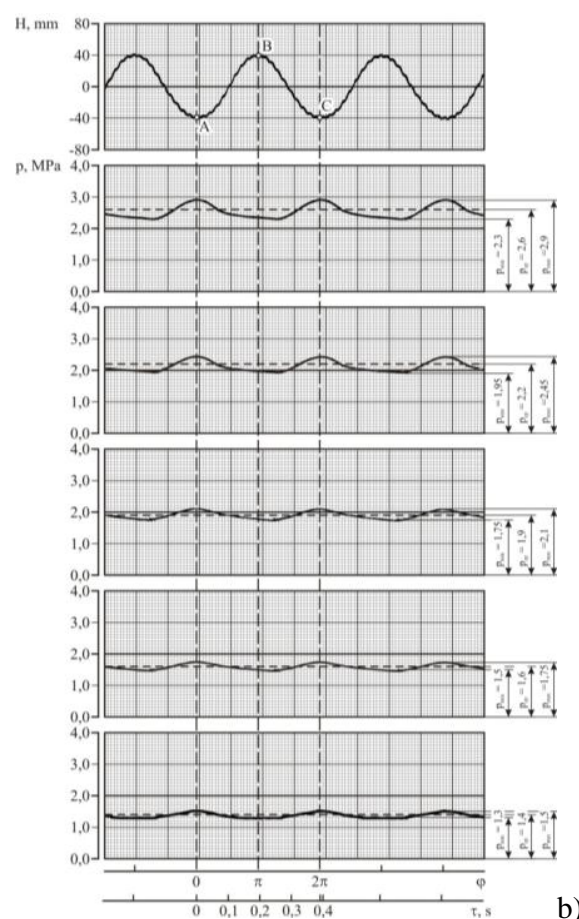

Fig. 10: Diagrams of the feed pressure of the mortar pump solution when pumping the solution $\mathrm{P}=10 \mathrm{~cm}$ : a) - with a combined pressure pulsation compensator; b) - with a combined compensator of increased volume

Mortar pump with a combined compensator of increased volume at $V_{\text {comp }}=47 \mathrm{dm}^{3}$ will pump the solution with a pulsation degree of $12 \%$ less in relation to the mortar pump with a combined pressure pulsation compensator.

In order to confirm the theoretical analysis of determining the parameters of the working process of the mortar pumps combined compensators, experimental research has been carried out. The diagrams of pump solution pressure feed with combined compensators of various design solutions were fixed and recorded with a compensating volume of 26 air liters ( 21 air liters is in a closed chamber and 5 liters - in a cylindrical one) and with a combined compensator of increased volume under the reduced compensated volume of 47 air liters ( 21 air liters is in a closed chamber and 26 liters - in a cylindrical one). According to the fixation results and diagrams recording of the of the pressure feed, the pulsation feed degree at different movements of the solution has been determined.

The results of fixation and recording the diagrams of the mortar pump pressure feed are shown in Fig. $4-6$, and the magnitudes of the solution feed degree are in table 2 and Fig.11. The results of determining the magnitude of solution feed pulsation degree are consistent with theoretical calculations.
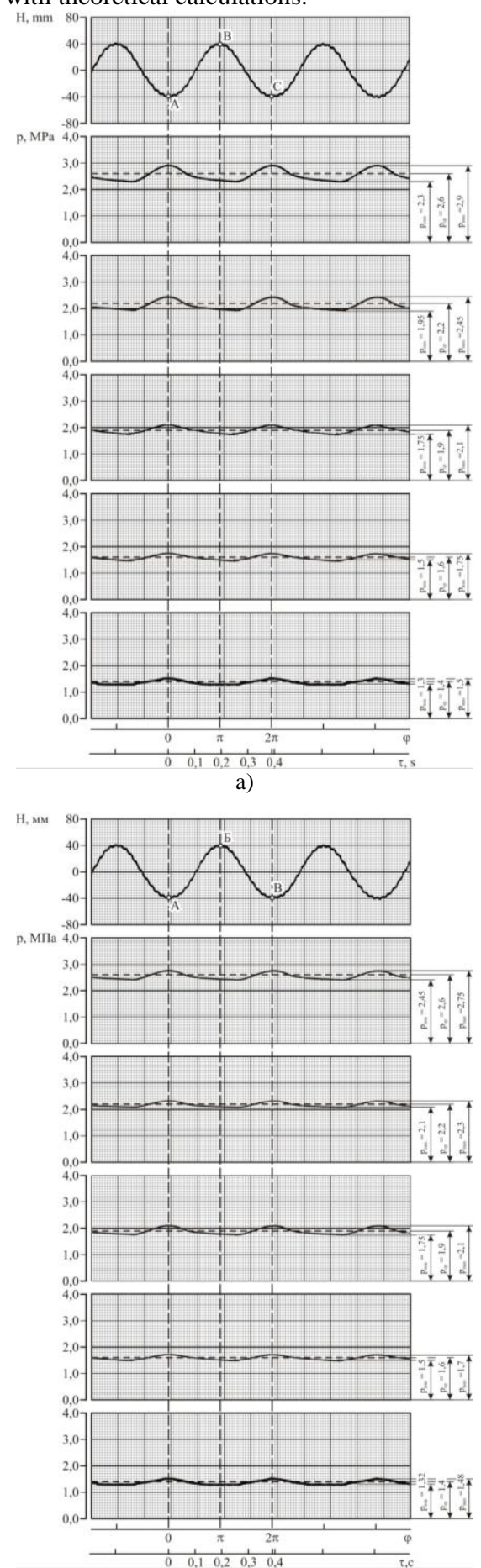

b)

Fig. 11: Diagrams of the feed pressure of the mortar pump solution when pumping the solution $\mathrm{P}=12 \mathrm{~cm}$ : a) - with a combined pressure compensator; b) - with a combined compensator of increased volume 
Table2 :Degree of pressure pulsations when feeding the solution under compensators of various constructive decisions

\begin{tabular}{|c|c|c|c|c|}
\hline 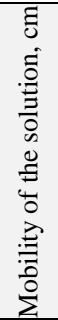 & 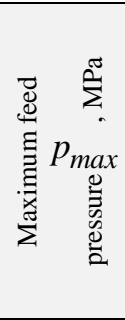 & 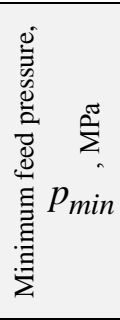 & 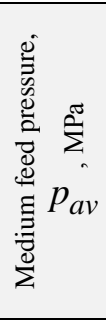 & 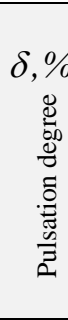 \\
\hline \multicolumn{5}{|c|}{$\begin{array}{l}\text { Single-piston mortar pump with combined } \\
\text { pulsation pressure compensator }\end{array}$} \\
\hline \multirow{5}{*}{ P8 } & 3,1 & 2,1 & 2,6 & 38,5 \\
\hline & 2,55 & 1,85 & 2,2 & 31 \\
\hline & 2,2 & 1,7 & 1,9 & 26,3 \\
\hline & 1,78 & 1,42 & 1,6 & 22,5 \\
\hline & 1,55 & 1,25 & 1,4 & 21 \\
\hline \multirow{5}{*}{ P10 } & 3,0 & 2,2 & 2,6 & 31 \\
\hline & 2,47 & 1,93 & 2,2 & 24,5 \\
\hline & 2,11 & 1,69 & 1,9 & 22,1 \\
\hline & 1,75 & 1,45 & 1,6 & 19,8 \\
\hline & 1,5 & 1,25 & 1,4 & 18 \\
\hline \multirow{5}{*}{ P12 } & 2,9 & 2,3 & 2,6 & 23 \\
\hline & 2,45 & 1,95 & 2,2 & 22,7 \\
\hline & 2,1 & 1,75 & 1,925 & 18 \\
\hline & 1,75 & 1,5 & 1,625 & 15,4 \\
\hline & 1,5 & 1,3 & 1,4 & 14 \\
\hline
\end{tabular}
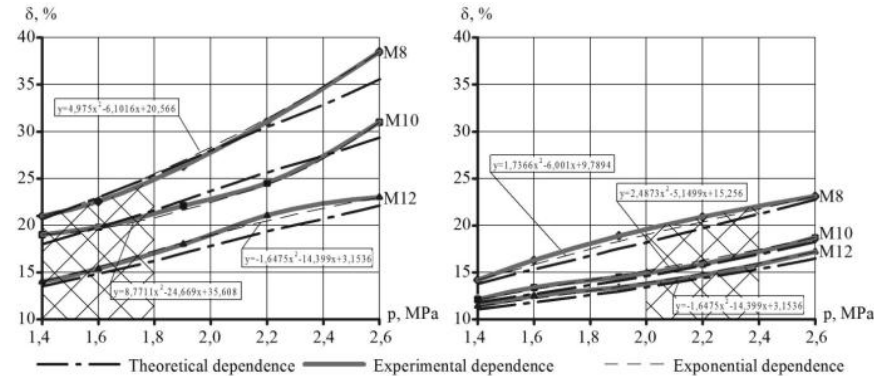

b)

Fig.12: Graphic dependences of the pulsation degree from the average solution pressure feed: 〈> - at P $8 \mathrm{~cm} ; \square-$ at P $10 \mathrm{~cm}$; $\square-$ at P $12 \mathrm{~cm} \mathrm{a)}$ with a combined pressure compensator; $b$ ) with a combined compensator of increased volume

Graphic dependencies of Fig. 12 indicate that the mortar pump with a compensator of an increased volume, whose degree of pulsations is $20 \ldots 25 \%$ less, works much more stable.

\section{Conclusions}

Theoretically and experimentally, the parameters of the compensator of increased volume for $V_{\text {comp }}=47 \mathrm{dm}^{3}$ have been established, which provides the feed pulsations when pumping the solutions $\Pi=8 \ldots 12 \mathrm{~cm}$ and the supply pressure $p=1,0 \ldots 3,5$ MPa at the level of $\delta=4,0 \ldots .23,0 \%$.

\section{References}

[1] Kukoba A. T. Changing the volume of the dissolved mixture when pumping with the solvent pump / Kukoba A.T., Korobko B.O. Vasiliev A. V. // Mechanization of construction.-2000. - No. 3.

[2] Onishchenko A. G. Method of calculation the return losses of a solution through a suction valve of a vertical differential mortar pump // Collection of scientific works (industrial engineering, construction) / Onishchenko A. G. , Kukoba A. T., Ustiantsev V. U.// Poltava State Technical Yuri Kondratyuk University. - Issue 3. - Poltava: Poltava State Technical University, 1998. - P. 3-6.
[3] O. G. Onyshchenko, M. V. Shapoval, A. Vasiliev Single-piston mortar pump with combined pressure compensator // Mechanization of Construction. Moscow - 2001. - No. 4. - P. 4-6.

[4] Chinayev I. A. Piston crank pumps. / Chinayev I. A. / - L.: Mechanical Engineering, Leningrad department- 1983. - $156 \mathrm{p}$.

[5] Parfenov E. P. Determination of piston mortar pump performance/ Parfenov E. P. // Mechanical tools and finishing machines: Informational Scientific and Technical Collection - Issue 4 Moscow: TsNIITEstroymash, 1972. - December 12-13.

[6] Mortelpumpen und ihre Entwicklung // "Fordern und Heben". 1969. - No. 15. (FRG)

[7] EP 0200026, INT. Cl 4 F 04 B 43/12, 15/02. Pumpe Neumuller Walter, Sturmer Gerhard. - 10/12/1986. - Patentblatt 86/45.

[8] Korobko B. (2016), Investigation of energy consumption in the course of plastering machine's work, Eastern-European Journal of Enterprise Technologies, 4/8 (82), 4 - 11. DOI: 10.15587/17294061.2016.73336.

[9] Vatin N, Gamayunova O 2014 Using plastering machines to improve the efficiency of finishing works AMM 635-637 pp. 20492053

[10] Chen, X. Experimental and modeling study of dynamic mechanical properties of cement paste, mortar and concrete [Text] / X. Chen, $\mathrm{S}$. Wu, J. Zhou // Construction and Building Materials. - 2013. Vol. 47. - P. 419-430. doi: 10.1016/j.conbuildmat.2013.05.063 